\title{
UPORABA $\beta$-GALAKTOZIDAZE NA PODROČJU ŽIVILSTVA IN PREHRANE
}

\author{
Nika ŽIBRAT ${ }^{1,2}$, Mihaela SKRT ${ }^{3}$, Polona JAMNIK ${ }^{3}$
}

Received May 21, 2017; accepted September 23, 2017.

Delo je prispelo 21. maja 2017, sprejeto 23. septembra 2017.

\begin{abstract}
Uporaba $\beta$-galaktozidaze na področju živilstva in prehrane
$\beta$-galaktozidaza je encim s hidrolitično in transgalaktozilacijsko aktivnostjo. Vrsta aktivnosti je odvisna od izvora encima. V industriji uporabljene $\beta$-galaktozidaze so pridobljene z rekombinantno produkcijo iz nitastih gliv Aspergillus sp. in kvasovk Kluyveromyces sp. V zadnjem času se vedno bolj preučujejo $\beta$-galaktozidaze, ki optimalno delujejo pri nizkih ali visokih temperaturah. $\mathrm{V}$ industrijskih procesih se $\beta$-galaktozidaza uporablja v obliki prostega encima ali v imobilizirani obliki. Imobilizacija pogosto ponuja večjo stabilnost encima, možnost ponovne uporabe ter znižanje stroškov. $\beta$-galaktozidaza se pretežno uporablja na področju živilstva in prehrane, v zadnjem času pa ima znatno vlogo tudi v medicini. Hidrolitična aktivnost $\beta$-galaktozidaze se že dolgo izkorišča za zmanjšanje vsebnosti laktoze v mleku, medtem ko z reakcijami transgalaktozilacije iz laktoze lahko sintetiziramo različne produkte, kot so galaktooligosaharidi, laktosaharoza in drugi. Prav slednji imajo velik potencial $\mathrm{v}$ živilski industriji zaradi pridobivanja izdelkov z zmanjšano vsebnostjo laktoze in izboljšanja prehranske vrednosti živil s proizvodnjo galaktooligosaharidov. Kljub temu je potrebno bolje razumeti reakcijske mehanizme kot tudi optimizirati procese, da bo uporaba encima za ta namen dosegla industrijsko raven.
\end{abstract}

Ključne besede: prehrana ljudi; živilska industrija; živilstvo; encimi; beta-galaktozidaza

\section{Potential applicaton of $\beta$-galactosidase in food science and nu- trition}

$\beta$-galactosidase is an enzyme with hydrolytic and transgalactosylation activity. The origin of the enzyme dictates the balance between both activities. Industrially used $\beta$-galactosidases are obtained with recombinant production from filamentus funghi Aspergillus sp. and yeasts Kluyveromyces sp. Recently thermostabile $\beta$-galactosidases have been subject of many research. The enzyme can be industrially used in free or immobilized form. Immobilization often provides better stability, reusability and lower expenses. Application of $\beta$-galactosidase is most common in food processing and nutrition, it is also used in medicine and ecology. Hydrolytic activity of the enzyme has long been used for reducing lactose content in milk, while transgalactosylitic activity is used for synthesis of products such as galactooligosaccharides, lactosucrose and others. The latter have a great potential in food industry for obtaining products with reduced lactose content and increasing of nutritional value by adding dietetic fibers such as galactooligosaccharides. Despite the potential it is vital that reaction mechanisms become better understood and optimization is in place in order to reach the usability of this enzyme at industrial level.

Key words: human nutrition; food industry; enzymes; beta-galactosidase

1 Univerza v Ljubljani, Biotehniška fakulteta, Oddelek za živilstvo, Ljubljana, Slovenija

2 Korespondenčni avtor, e-naslov: nikazibrat@gmail.com

3 Isti naslov kot: 1 


\section{UVOD}

$\beta$-galaktozidaza (EC 3.2.1.23) je encim, ki ima hidrolitično kot tudi transgalaktozilacijsko aktivnost. Hidrolizira $\beta(1 \rightarrow 4)$ glikozidno vez v $\beta$-D-galaktozidih, pri tem pa se odcepi $\beta$-D-galaktoza. Pri transgalaktozilaciji se glikozilna skupina prenese na D-galaktozno enoto laktoze (Obed Otieno, 2010). Hidrolitična in transgalaktozilacijska aktivnost je v veliki meri odvisna od izvora encima in koncentracije galaktoznega donorja in akceptorja. $\beta$-galaktozidaze iz mikroorganizmov vrste Aspergillus niger in Bacillus circulans imajo visoko transgalaktozilacijsko aktivnost, medtem ko tiste iz rodu Kluyeromyces izražajo visoko hidrolitično, a nižjo transgalaktozilacijsko aktivnost (Guerrero in sod., 2015). V zadnjem času so vedno bolj proučevane in priljubljene za uporabo $\mathrm{v}$ industriji $\beta$-galaktozidaze, ki optimalno delujejo pri nizkih ali visokih temperaturah (Oliveira, Guimarães in Domingues, 2011). Termostabilne $\beta$-galaktozidaze so pridobljene iz organizmov vrst Aspergillus niger, Bacilus. stearothermophillus, Pyrococcus woesei, Thermus sp. in so stabilne pri temperaturah od 35 do $80^{\circ} \mathrm{C}$. $\beta$-galaktozidaze iz psihrofilnih organizmov, kot so Arthrobacter psychrolactophilus in Pseudoaltermonas haloplanktis, so stabilne $\mathrm{v}$ temperaturnem območju od 0 do $25^{\circ} \mathrm{C}$ (Panesar in sod., 2006; Sheik in Gunasekaran, 2010; Husain, 2010).

\section{VIRI $\beta$-GALAKTOZIDAZE}

$\beta$-galaktozidaza je lahko pridobljena iz mnogih virov, kot so mikroorganizmi, rastline in živali. Lastnosti encima se glede na vir med seboj razlikujejo. Mikroorganizmi imajo prednost pri industrijski uporabi, saj omogočajo hitro namnoževanje, lažje rokovanje ter visoke izkoristke. $\beta$-galaktozidaze iz rastlinskih in živalskih virov imajo majhno komercialno vrednost (Panesar in sod., 2010). Encim je tako izoliran iz mikroorganizmov vrst Aspergillus niger, Bacillus megaterium, Beijerinckia indica, Bifidobacterium infantis, Bifidobacterium longum, Enterobacter cloacae, Geobacillus stearothermophillus, Kluveromyces marxianus, Lactobacullus sp., Lactobacillus reuteri, Penicillum expansum in uporabljen za produkcijo galaktoze, glukoze, galakto-oligosaharidov in heteropolisaharidov. Najbolj pogoste $\mathrm{v}$ industriji uporabljene $\beta$-galaktozidaze so pridobljene z rekombinantno produkcijo iz nitastih gliv Aspergillus spp. in kvasovk Kluyveromyces spp. (Zadow, 1984; Siso, 1996; Panesar in sod., 2006; Husain, 2010). Glavni razlog za to sta sprejemljiva produktivnost in donos. Prav tako imajo produkti, pridobljeni iz omenjenih mikroorganizmov, status GRAS - ang. generally recognised as safe, kar pomeni, da so varni za uživanje, kar je nujno za aplikacije na področju hrane (Siso, 1996; Panesar in sod., 2006;
Kosseva in sod., 2009). Pri nitasti glivi Aspergillus spp. se $\beta$-galaktozidaza proizvaja ekstracelularno. Encim ima optimalen $\mathrm{pH}$ v kislem območju $(2,5-5,4)$ in visoko optimalno temperaturo, kar omogoča njegovo uporabo pri temperaturah do $50^{\circ} \mathrm{C}$ (Zadow, 1984; Panesar in sod., 2006). Encim se uporablja za hidrolizo kisle sirotke, ki je stranski produkt predelave mleka $\mathrm{v}$ sveže in mehke sire (Yang in Silva, 1995). Nasprotno pa kvasovka Kluyveromyces spp. proizvaja intracelularni encim. Substrat laktoza se najprej $\mathrm{s}$ pomočjo permeaze prenese $\mathrm{v}$ notranjost celice, kjer jo encim hidrolizira do glukoze in galaktoze (Guimarães in sod., 2010). Encim ima optimalen pH delovanja blizu nevtralnemu $(6,0-7,0)$ ter se tako lahko uporablja predvsem pri hidrolizi mleka in sladke sirotke, ki nastane pri predelavi mleka v trde sire (Zadow, 1984; Yang in Silva, 1995; Panesar in sod., 2006). Ker se encim proizvaja intracelularno, je za njegovo pridobivanje potrebna kemijska ali mehanska obdelava celic (Panesar in sod., 2006). V zadnjem času preučujejo še $\beta$-galaktozidaze iz mikroorganizmov vrste Aspergillus oryzae (Duarte in sod., 2017; Guerrero in sod., 2017), Streptococcus thermophilus (Geiger in sod, 2016), Kluyveromyces lactis (Santibáñez in sod., 2016), Lactobacilus helveticus (Watson in sod., 2016), Planococcus sp. (Mahdian in sod., 2016), Escherichia coli (Duan in sod., 2017), Bacillus circulans (Duarte in sod., 2017), Rahnella sp. (Fan in sod., 2015), Caldicellulosiruptor saccharolyticus (Shen in sod., 2016) ter Teratosphaeria acidotherma (Yamanda in sod., 2017).

\section{NAČINI UPORABE ENCIMA}

$\beta$-galaktozidazo lahko uporabimo na dva načina: kot prost encim v raztopini ali kot imobiliziran encim (Gänzle in sod., 2008). Uporaba prostega encima je tehnično lažja, vendar bolj potratna in hkrati dražja, saj raztopljenega encima ni mogoče ponovno uporabiti. To predstavlja glavno oviro pri njegovi uporabi v industrijskih procesih. Membranska tehnologija, ki temelji na ultrafiltraciji na membranah, ki niso permeabilne za $\beta$-galaktozidazo, je metoda, ki vzbuja zanimanje zaradi možnosti ponovne uporabe encima (Richmond in sod., 1981; Gosling in sod., 2010). Imobilizacijske tehnike za uporabo encima so sicer tehnično zahtevnejše, vendar zagotavljajo ponovno uporabo encima in možnost aplikacije $\mathrm{v}$ kontinuirnih procesih ter zagotavljajo večjo stabilnost encima. Prav tako lahko $\mathrm{v}$ bioprocesih uporabimo cele celice ter se tako izognemo višjim stroškom zaradi izolacije encima. Velika slabost uporabe imobiliziranih celic je slaba permeabilnost celične membrane za laktozo. Permeabilnost lahko povečamo $\mathrm{z}$ obdelavo celic s kemijskimi agensi, kot so detergenti ali topila (Panesar in sod., 2006). 


\subsection{IMOBILIZACIJA}

Imobilizacija je vezava encima $\mathrm{v} / \mathrm{na}$ medij, $\mathrm{s}$ čimer je encim ločen od reakcijske zmesi, hkrati pa je omogočen stik encima s substratom (Husain, 2010). Je izjemno koristen proces, ki se uporablja predvsem za industrijske aplikacije. Poviša lahko uporabnost encima, prav tako poveča njegovo stabilnost med shranjevanjem. Imobilizacija v/na ustrezen medij lahko stabilizira encim na spremembe temperature in $\mathrm{pH}$. Imobiliziran encim lahko večkrat uporabimo, kar zmanjša stroške zaradi ponovnega pridobivanja in čiščenja encima (Wahba, 2016). Namesto izolacije encima lahko imobiliziramo celice, v katerih se encim nahaja. Pri tovrstni imobilizaciji so stroški manjši, ker ni potrebna izolacija, hkrati pa so nekateri encimi bolj stabilni, kadar so imobilizirani v svojem naravnem okolju (Genari, Passos in Passos, 2003; Krajewska, 2004). Znane so različne tehnike za imobilizacijo $\beta$-galaktozidaze, kot so ujetje znotraj nosilca (ang. entrapment), kapsulacija, adsorbcija, kovalentna vezava (križno povezovanje) $\mathrm{z}$ možnostjo kombinacije tehnik (Guerrero in sod., 2017). Izbira medija za imobilizacijo encima je zelo pomembna, saj je $\mathrm{v}$ določenih primerih potrebna predhodna aktivacija medija za uspešno imobilizacijo encima, posledica tega pa je lahko interakcija med medijem in encimom, ki privede do inaktivacije samega encima (Rueda in sod., 2016).

Ločba imobiliziranega encima od reakcijske mešanice je nujna zahteva za uporabo imobilizacijskih tehnik v živilski industriji (Elnashar, 2010; Zucca in Sanjust, 2014). Od uporabljenih materialov za imobilizacijo je zaradi ugodnih lastnosti, kot so biokompatibilnost, fiziološka inertnost, biorazgradljivost na neškodljive produkte, netoksičnost in odlična afiniteta do proteinov, zelo primeren hitozan (Krajewska, 2004). Hitozan je skupno ime za veliko skupino hitinov, deacetiliranih do različnih stopenj. Sestavljen je pretežno iz 2-amino-2-deoksi-D-glukopiranoznih enot, povezanih z ß-1,4-vezjo (Strnad in sod., 2007). Komercialno se pridobiva $\mathrm{z}$ deacetilacijo hitina, polisaharida, ki se nahaja $\mathrm{v}$ lupinah rakov. Kapsulacijske sposobnosti hitozanskih podlag za imobilizacijo so lahko izboljšane $\mathrm{z}$ uporabo reagentov, kot so glutaraldehid, genipin in drugi (Cauich-Rodriguez in sod., 1996; Muzzarelli, 2009). Klein in sod. (2016) so imobilizirali $\beta$-galaktozidazo, pridobljeno iz nitastih gliv vrste $A$. oryzae, na hitozansko podlago $\mathrm{z}$ reagentom genipin in jo uporabili za pridobivanje galaktooligosaharidov. Optimalna vrednost $\mathrm{pH}$ encima se je $\mathrm{z}$ imobilizacijo premaknila $\mathrm{v}$ bolj kislo območje, s 4,5-5,0 pri prostem encimu na 4 , prav tako pa je imobiliziran encim ohranil višjo aktivnost pri $\mathrm{pH}=3 \mathrm{v}$ primerjavi s prostim encimom. $\mathrm{Z}$ uporabo genipina namesto glutaraldehida kot zamreževalnega reagenta se lahko izognemo škodlji- vim učinkom uporabe slednjega ter zato razširimo prej omejeno uporabo hitozana $\mathrm{v}$ živilski industriji (Klein in sod., 2016). Dwevedi in Kayastha (2009) sta imobilizirala $\beta$-galaktozidazo iz graha (PsBGal) na zamrežen dekstran in hitozan. Pri PsBGal, imobilizirani na hitozan, ni bilo zaznati izgube aktivnosti v 40 dneh, medtem ko je PsBGal, imobilizirana na dekstranu, začela izgubljati aktivnost že po 10 dneh hranjenja pri $4^{\circ} \mathrm{C}$. Po 10 izpiranjih je bila izguba aktivnosti pri hitozan imobilizirani PsBGal zanemarljiva, medtem ko se je pri dekstran imobilizirani PsBgal aktivnost zmanjšala za $70 \%$. To kaže, da se encim močneje veže na hitozan kot na dekstran (Dwevedi in Kayastha, 2009). Duarte in sod. (2017) so na hitozan kovalentno imobilizirano $\beta$-galaktozidazo uporabili za bioproces sinteze prebiotika laktosaharoze. Imobilizacija je izboljšala stabilnost encima pri $50^{\circ} \mathrm{C}$ za 260 -krat. Z uporabo saharoze $\left(300 \mathrm{~g} \mathrm{l}^{-1}\right)$, laktoze $\left(300 \mathrm{gl}^{-1}\right)$ in hitozana $\left(8,5 \mathrm{gl}^{-1}\right)$ je encim ohranil maksimalno aktivnost tudi po tridesetih ciklih uporabe (Duarte in sod., 2017).

Kishore in Kayastha (2012) sta $\beta$-galaktozidazo, izolirano iz čičerike (C. arietinum), imobilizirala na alkilamin. Optimalna vrednost $\mathrm{pH}$ se je premaknila v kislo območje. Optimalna temperatura se ni spremenila, vendar je encim pokazal boljšo temperaturno stabilnost $\mathrm{v}$ primerjavi s prostim encimom. Imobiliziran encim je po treh mesecih hranjenja $\mathrm{v} 25 \mathrm{mM}$ fosfatnem pufru pri $4{ }^{\circ} \mathrm{C}$ ohranil več kot $80 \%$ začetne aktivnosti, medtem ko je encim, hranjen v suhem okolju pri sobni temperaturi, ohranil $72 \%$ začetne aktivnosti. Imobilizirana $\beta$-galaktozidaza je ohranila $82 \%$ prvotne aktivnosti po 15-ih zaporednih šaržah uporabe (Kishore in Kayastha, 2012).

Wahba (2016) je kovalentno imobilizirala $\beta$-galaktozidazo iz nitastih gliv vrste $A$. oryzae na podlago iz kalcijevega pektinata, tretiranega s polietileniminom in glutaraldehidom. Po imobilizaciji $\beta$-galaktozidaze na omenjen nosilni material je encim pokazal premik optimalne temperature delovanja s $55^{\circ} \mathrm{C}$ (Vera in sod., 2011) na $60^{\circ} \mathrm{C}$ ter večjo toleranco na visoke temperature. Imobilizirana $\beta$-galaktozidaza je ohranila $80,2 \%$ aktivnosti pri temperaturi $65^{\circ} \mathrm{C}$ in $22,7 \%$ pri temperaturi $70^{\circ} \mathrm{C}$, medtem ko je prosti encim ohranil $49,5 \%$ in $9,8 \%$ aktivnosti pri zgoraj navedenih temperaturah. Optimalni $\mathrm{pH}$ delovanja imobiliziranega encima je $\mathrm{v}$ širšem območju $\mathrm{pH}$ vrednosti pomaknjen $\mathrm{k}$ bolj kislim vrednostim $(3,2-5,4)$ v primerjavi $\mathrm{z}$ optimalno $\mathrm{pH}$ vrednostjo delovanja samega izoliranega encima $(5,3)$. Gel iz kalcijevega pektinata, tretiranega s polietileniminom in glutaraldehidom, je zaradi svoje mehanske stabilnosti in ugodnega vpliva na aktivnost encima primeren za industrijske aplikacije (Wahba, 2016). Huerta in sod. (2011) so imobilizirali $\beta$-galaktozidazo iz nitaste glive vrste $A$. oryzae na glioksil-agarozo, $\mathrm{z}$ namenom sinteze galaktooligosa- 
haridov (GOS) iz medija z visoko koncentracijo laktoze. Imobiliziran encim je pokazal odlično stabilnost ter izkoristek procesa, saj je po desetih 3-urnih šaržah 1 mg imobiliziranega encima sintetiziralo kar 7,9 g GOS, medtem ko je prost encim pri enakih pogojih sintetiziral le 2,9 g GOS. Učinkovitost encima se je z imobilizacijo povečala za $190 \%$, prav tako je encim po desetih šaržah ohranil $75 \%$ začetne aktivnosti (Huerta in sod., 2011). Neri in sod. (2009) so za proizvodnjo galaktooligosaharidov imobilizirali na magnetni polisiloksan-polivinil alkohol (mPOS-PVA) $\beta$-galaktozidazo iz nitaste glive vrste A. oryzae. V $50 \%(\mathrm{w} / \mathrm{v})$ reakcijski zmesi pri pH 4,5 in temperaturi $40{ }^{\circ} \mathrm{C}$ je bil izkoristek $55 \%$. Maksimalna dosežena koncentracija GOS je bila $26 \%$ glede na vsebnost skupnih sladkorjev, trisaharidi so predstavljali $81 \%$ sintetiziranih GOS (Neri in sod., 2009).

\subsection{UPORABNOST ENCIMA}

$\beta$-galaktozidaza je $\mathrm{v}$ živilski industriji najpogosteje uporabljena za pridobivanje laktozno hidroliziranih mlečnih izdelkov (Hsu, Yu in Chou, 2005; Heyman, 2006; Neri in sod., 2008). Transgalaktozilacijska aktivnost pa se izkorišča za pridobivanje prebiotičnih produktov, kot so galaktooligosaharidi, laktosaharoza, laktuloza, galaktoziltrehaloza in gal-sorbitol (Oliveira, Guimarães in Domingues, 2011).

$\beta$-galaktozidaza je pomembna pri laktozni intoleranci, kjer zaužitje encima pomaga pri prebavi laktoze. Poleg mleka je glavni vir laktoze sirotka, ki nastane pri predelavi mleka $\mathrm{v}$ sir. $\beta$-galaktozidaza in njena hidrolitična aktivnost pri razgradnji laktoze je zato učinkovito sredstvo za zmanjševanje negativnega vpliva sirotke kot glavnega stranskega produkta proizvodnje sira na okolje, hkrati pa omogoča pretvorbo sirotke $\mathrm{v}$ široko uporabne produkte (Bailey in sod., 1982; Terrell in sod., 1984, Geiger in sod., 2016).

Kljub temu, da $\beta$-galaktozidazo zaradi njene hidrolitične aktivnosti tradicionalno uporabljamo $\mathrm{v}$ mlekarski industriji za pridobivanje mleka brez laktoze, je na tem področju še veliko možnosti za razvoj. Tukaj je pomembno omeniti $\beta$-galaktozidaze, ki so aktivne pri nizkih temperaturah (Song in sod., 2010) in se lahko uporabijo za hidrolizo laktoze $\mathrm{v}$ ohlajenem mleku, kot tudi termofilne, ki omogočajo hidrolizo laktoze sočasno s postopkom pasterizacije pri pridobivanju mleka $\mathrm{z}$ zmanjšano vsebnostjo laktoze (Oliveira in sod., 2011).

\subsubsection{HIDROLIZA LAKTOZE V MLEKU Z NA- MENOM IZBOLJŠANJA TEHNOLOŠKIH IN PREHRANSKIH LASTNOSTI MLEKA}

$\beta$-galaktozidaza katalizira hidrolizo laktoze $\mathrm{v}$ dva monosaharida, glukozo in galaktozo.

Mleko s hidrolizirano laktozo ima številne prednosti: (1) hitrejša fermentacija, (2) večja sladkost mleka, (3) višja topnost glukoze in galaktoze v primerjavi z laktozo, (4) večja stabilnost mleka s hidrolizirano laktozo, (5) hitrejši padec $\mathrm{pH} v \mathrm{v}$ siru, proizvedenem iz mleka s hidrolizirano laktozo, ter posledično boljše senzorične lastnosti (Jokar in Karbassi, 2009). Hidroliza laktoze je zaradi povečanja sladkosti mleka $\mathrm{v}$ sladoledu in sladkih mlečnih nadevih lahko alternativa uporabi saharoze ali škrobnim sirupom (Zadow, 1984; Siso, 1996). Panesar in sod. (2007) so zmanjšali vsebnost laktoze v mleku $\mathrm{z}$ uporabo kvasovk vrste K. marxianus. Kvasovka je pri optimiziranih pogojih hidrolizirala $89 \%$ laktoze v mleku (Panesar in sod., 2007). Jokar in Karbassi (2011) navajata, da se senzorične lastnosti navadnega mleka in mleka brez laktoze $\mathrm{v}$ večji meri ne razlikujejo.

Najpogosteje se za hidrolizo laktoze v mleku uporabljajo rekombinantne $\beta$-galaktozidaze. Uporaba encima iz psihrotrofnih bakterij, kot so Pseudoaltermonas (Cieśliński in sod., 2005) in Lactobacillus acidophillus (Pan in sod., 2010), izraženega v bakterijah vrste E. coli, je bila uspešna z $90-\%$ hidrolizo laktoze v 28 urah pri $15^{\circ} \mathrm{C}$ ter $73-\%$ hidrolizo laktoze v 30 urah pri $10^{\circ} \mathrm{C}$ (Cieśliński in sod., 2005; Pan in sod., 2010). Na hitinu imobilizirana $\beta$-galaktozidaza iz arhebakterij vrste Pyrococcus woe$s e i$, izražena v bakterijah vrste $E$. coli, je pokazala veliko aktivnost in termostabilnost pri $75^{\circ} \mathrm{C}$ (Daabrowski in sod., 2000). Yuan in sod. (2008) so termostabilno $\beta$-galaktozidazo iz bakterij vrste Alicyclobacillus acidocaldarius izrazili v kvasovki rodu Pichia. Rekombinanten encim je hidroliziral $48 \%$ laktoze v mleku v 60 minutah pri $65^{\circ} \mathrm{C}$. Stopnja hidrolize je bila mnogo višja v raztopini laktoze pri enakih pogojih v primerjavi z mlekom. To poraja vprašanje o uporabnosti $\beta$-galaktozidaze iz bakterije $A$. acidocaldarius na industrijski ravni ter o morebitnih inhibitornih učinkih drugih sestavin $\mathrm{v}$ mleku na njeno aktivnost (Yuan in sod., 2008). Rekombinantna $\beta$-galaktozidaza iz bakterije Bacillus stearothermophilus je pokazala visoko aktivnost pri temperaturah do $75^{\circ} \mathrm{C}$ in stabilnost pri višjih temperaturah. Temperaturne lastnosti in delovanje pri nevtralnem $\mathrm{pH}$ kaže, da je encim idealen kandidat za aplikacije $\mathrm{v}$ proizvodnji mleka $\mathrm{z}$ zmanjšanim deležem laktoze $\mathrm{z}$ možnostjo uporabe med pasterizacijskimi postopki (Chen in sod., 2008). Chen in sod. (2009) so leto kasneje rekombinantno $\beta$-galaktozidazo iz Bacillus stearothermophilus imobilizirali na hitozan s Tris fosfinom (THP). Imobiliziran encim 
je pokazal boljšo aktivnost, termostabilnost, sposobnost skladiščenja in ponovne uporabe $\mathrm{v}$ primerjavi s prostim encimom. Delež hidrolizirane laktoze je bil pri $70^{\circ} \mathrm{C} \mathrm{v}$ dveh urah $80 \%$ (Chen in sod., 2009).

Jokar in Karbassi (2011) sta za proizvodnjo $\beta$-galaktozidaze uporabila bakterije vrste Lactobacillus delbrueckii ssp. bulgaricus. Sirotkin permeat sta uporabila kot gojišče za namnoževanje bakterij. Pri aktivnosti encima v mleku $0,418 \mathrm{U} / \mathrm{ml}$ je bila stopnja hidrolize $78 \%$, kar je bila optimalna aktivnost. Pri višji aktivnosti encima je mleko koaguliralo. Pri komercialni $\beta$-galaktozidazi z aktivnostjo $0,512 \mathrm{U} \mathrm{ml}^{-1}$ je bila stopnja hidrolize laktoze 90 \% (Jokar in Karbassi, 2011). Li in sod., (2015) pa poročajo o uporabi komercialnega encima, pridobljenega iz kvasovke rodu Kluyveromyces, za hidrolizo laktoze $\mathrm{z}$ namenom zmanjšanja vsebnosti skupnih sladkorjev $\mathrm{v}$ čokoladnem mleku.

\subsection{2 $\beta$-GALAKTOZIDAZA ZA LAJŠANJE SIMP- TOMOV LAKTOZNE INTOLERANCE}

Vsaj $65 \%$ odrasle populacije na svetu ima zmanjšano sposobnost prebave laktoze. Laktozna intoleranca ali hipolaktazija je stanje, pri katerem ima posameznik zmanjšano sposobnost prebaviti laktozo zaradi zmanjšane količine encima $\beta$-galaktozidaze ali pomanjkanja le-tega. Hipolaktazija v otroštvu je posledica mutacije na $L C T$ genu, ki je nosilec genskega zapisa za $\beta$-galaktozidazo. Hipolaktazija v odraslem življenju je posledica zmanjšane sinteze $\beta$-galaktozidaze v celicah tankega črevesja, enterocitih. Najpogostejša je v vzhodni Aziji, kjer za njo trpi kar 90 \% prebivalcev. Prav tako je zelo pogosta v državah Zahodne Afrike, arabskih ter judovskih državah (Institute for Quality and Efficiency in Health Care, 2015). Imobilizirana ali prosta $\beta$-galaktozidaza $\mathrm{z}$ oralnim vnosom pred zaužitjem hrane lahko pomaga pri lajšanju težav pacientov z laktozno intoleranco. Težave predstavlja stabilnost obeh oblik encima po zaužitju, saj se lahko encim razgradi, preden doseže tanko črevo. Alternativa uporabi standardnih imobilizirajočih agensov je lahko uporaba prepustnega polimernega matriksa, kot je polisaharidni hidrogel $\mathrm{z}$ aktivno površino, ki omogoča poznejše sproščanje encima (Ahmadi in sod., 2015).

\subsubsection{HIDROLIZA LAKTOZE V SIROTKI IN PRO- IZVODNJA ETANOLA}

Sirotka je stranski produkt predelave mleka, ki nastane ob koagulaciji kazeinov pri proizvodnji sira. $\beta$-galaktozidaza in njena hidrolitična aktivnost pri razgradnji laktoze je zato učinkovito sredstvo za zmanjše- vanje negativnega vpliva sirotke, kot glavnega stranskega produkta proizvodnje sira, na okolje. Letno na globalni ravni proizvedemo več kot 160 milijonov ton sirotke, kar pomeni približno 6 milijonov ton laktoze (Guimarães, Teixeira in Domingues, 2010). Glavni komponenti sirotke, beljakovine in laktozo, lahko ločimo z ultrafiltracijo. Rezultat so sirotkine beljakovine in sirotkin permeat, ki lahko vsebuje kar $85 \%$ laktoze v suhi snovi (Geiger in sod., 2016). S pomočjo $\beta$-galaktozidaze lahko sirotko predelamo $\mathrm{v}$ surovino $\mathrm{s}$ širšo uporabnostjo (Bailey in sod., 1982; Terrell in sod., 1984, Geiger in sod., 2016) in jo uporabimo kot cenen substrat za mikroorganizme, negativne na laktozo, ali kot medij, ki promovira produkcijo uporabnih produktov. Prav tako lahko rekombinantno $\beta$-galaktozidazo uporabimo pri bioremediaciji sirotke, vendar je raziskav na tem področju malo (Oliveira in sod., 2011). Uporaba laktoze iz sirotke za pridobivanje etanola se na komercialni ravni uporablja že vsaj od leta 1970 (Lyons in Cunningham, 1980; Guimaraes in sod., 2010). Fermentacija laktoze v sirotki direktno v etanol ni komercialno uspešna metoda, razlog so predvsem nizki donosi in majhna toleranca mikroorganizmov na alkohol (Coté in sod., 2004). Sevi kvasovk iz rodu Kluyveromyces, še posebej $K$. marxianus, so bili med prvimi mikroorganizmi, uporabljenimi za pridobivanje etanola iz sirotkine laktoze. Domnevno majhna ozmotska toleranca je vzrok za dolgotrajno fermentacijo in relativno majhno količino etanola 2,5-4,4 \% (v/v), pridobljenega iz gojišča z nizko začetno koncentracijo laktoze (5,0 \%). Zato kvasovka Kluyveromyces ni najbolj primerna za fermentacijo laktoze do etanola (Guimaraes in sod., 2010). Jin in sod. (2016) so uporabili kvasovko S. cerevisiae za produkcijo etanola v gojišču, ki je vsebovalo $25 \%$ pšenice in sirotkin permeat. Sočasno so v mešanico pšenice in permeata dodali še $\beta$-galaktozidazo iz nitaste glive vrste $A$. oryzae in kvasovk vrste $K$. lactis z namenom hidrolize laktoze. $\beta$-galaktozidaza iz nitaste glive $A$. oryzae je hidrolizirala kar 75,5 \% laktoze, medtem ko je bil pri kvasnem encimu izkoristek slabši, in sicer 13,7 \%. Razlog za to je razlika $\mathrm{v}$ optimalni vrednosti $\mathrm{pH}$ obeh encimov, saj je optimalna vrednost $\mathrm{pH}$ za $\beta$-galaktozidazo iz nitaste glive A. oryzae 4,5 (Grosova in sod., 2008) veliko bližja vrednosti $\mathrm{pH}$ fermentacije (4), medtem ko je optimalni $\mathrm{pH} \beta$-galaktozidaze iz kvasovke $K$. lactis že v nevtralnem območju 6,5-7,0 (Dagbagli in Goksungur, 2008). $\beta$-galaktozidaza iz nitaste glive vrste $A$. oryzae je zato primernejša za hidrolizo laktoze pri kislih pogojih fermentacije. Ugotovili so, da sirotkin permeat lahko uspešno nadomesti del pšenice kot substrata za fermentacijo do etanola (Jin in sod., 2016). Uporaba $\beta$-galaktozidaze iz nitastih gliv se tako $\mathrm{v}$ prehranski industriji priporoča za hidrolizo laktoze iz kisle sirotke (Panesar in sod., 2010). Divji sevi kvasovk vrste Saccharomyces cerevisiae, 
ki nimajo $\beta$-galaktozidaze, lahko proizvajajo etanol iz hidrolizirane sirotke, vendar gre za mutante, ki so odporni na katabolno represijo z glukozo in galaktozo (Bailey in sod., 1982; Terrell in sod., 1984). Domingues in sod. (2005) so s transformirano kvasovko S. cerevisiae, ki izraža $\beta$-galaktozidazo, dosegli koncentracijo etanola $9 \mathrm{~g} \mathrm{l}^{-1}$ pri začetni koncentraciji laktoze $50 \mathrm{~g} \mathrm{l}^{-1}$ in stopnji redčenja $0,45 \mathrm{~h}^{-1}$ (Domingues in sod., 2005).

$\beta$-galaktozidaze iz kvasovk imajo običajno optimalen $\mathrm{pH}$ v kislem območju in so zato bolj primerne za hidrolizo laktoze v kisli sirotki. Rekombinantna $\beta$-galaktozidaza iz nitaste glive vrste Aspergillus niger je bila izražena v kvasovkah vrste Saccharomyces cerevisi$a e$ in uporabljena za hidrolizo laktoze v sirotkinem permeatu. V 20 urah pri $30{ }^{\circ} \mathrm{C}$ je bila dosežena $90-\%$ biokonverzija laktoze. Sočasno ob izločanju rekombinantne $\beta$-galaktozidaze iz celic $S$. cerevisiae je nastajal etanol (Domingues in sod., 2002).

\subsubsection{PROIZVODNJA GALAKTOOLIGOSAHARI- DOV (GOS) IN LAKTOSAHAROZE}

Galaktooligosaharidi so ogljikovi hidrati, ki so sestavljeni iz 2-20 molekul galaktoze in 1 molekule glukoze. Spadajo med prebiotike. Po zaužitju potujejo po prebavnem traktu, kjer jih hidrolizirajo in fermentirajo črevesne bakterije (Delzenne, 2003). Raziskave kažejo, da blagodejno vplivajo na črevesno mikrobioto, saj spodbujajo proliferacijo koristnih bifidobakterij in laktobacilov v črevesju, kateri prispevajo k zdravju človeka. Danes se uporabljajo predvsem za prehrano novorojenčkov (Patel in Goyal, 2010; Sabater in sod., 2015). Raziskave kažejo, da bi se GOS lahko uporabljali za zdravljenje zaprtja (Hamilton-Miller, 2004).

$\mathrm{Za}$ transgalaktozilacijske reakcije navadno uporabljamo mikroorganizme vrst Aspergillus oryzae in $\mathrm{Ba}$ cillus circulans, in sicer zaradi ugodnega razmerja med transgalaktozilacijsko in hidrolitično aktivnostjo (Guererro in sod., 2011; Urrutia in sod., 2013). Prav tako so $\mathrm{v}$ uporabi Kluyveromyces lactis, Lactobacillus plantarum, Bifidobacterium infantis, Geobacillus stearothermophilus, Alkalilactibacillus ikkese in Bacillus stearothermophilus. Vsi, razen A. ikkense in B. stearothermophillus, so mezofilni mikroorganizmi (Oliveira in sod., 2011). Veliko novejših raziskav proučuje mikroorganizme, ki sintetizirajo $\beta$-galaktozidazo z izboljšanim izkoristkom reakcij za pridobivanje galaktooligosaharidov (Neri in sod., 2009), vendar je donos encimske sinteze GOS redko višji od 40 \% (Córdova in sod., 2017). Srivastava in sod. (2015) so z uporabo $\beta$-galaktozidaze iz kvasovk vrste Kluyveromyces marxianus iz laktoze sintetizirali GOS s 36-\% donosom. Produkt je vseboval tri- in tetra-oligosaharide. Li in sod. (2009) so v kvasovkah vrste S. cerevisiae klonirali gen iz nitaste glive vrste $P$. expansum F3, ki kodira $\beta$-galaktozidazo. Encim se izraža na površini kvasnih celic. Tako transformirana kvasovka je uspešno porabljala laktozo za produkcijo GOS. Stranski produkti reakcije so bili glukoza in manjše količine galaktoze. Medtem ko je kvasovka glukozo uporabila kot vir ogljika, je galaktoza služila kot induktor za izražanje $\beta$-galaktozidaze. Nastanek manjših količin galaktoze je bil torej ključen za nadaljnji potek reakcij (Li in sod, 2009). González-Delgado in sod. (2016) so z optimizacijo parametrov, kot so $\mathrm{pH}$, začetna koncentracija laktoze in reakcijski čas, želeli izboljšati sintezo tri- in tetra-GOS z $\beta$-galaktozidazo iz kvasovk vrste Kluyveromyces lactis. Pri aktivnosti encima $5 \mathrm{U} \mathrm{ml}^{-1}, \mathrm{~T}=40^{\circ} \mathrm{C}$ in začetni koncentraciji laktoze $250 \mathrm{~g}^{-1}$ so ob reakcijskem času treh ur dosegli $12,2-\%$ donos GOS. S pomočjo $\mathrm{pH}$ jim je uspelo spremeniti sestavo produkta, natančneje delež tri-GOS in tetra-GOS. Pri pH 6,0 so dosegli 10,9-\% delež tri-GOS, pri pH 7,0 pa $1,4-\%$ delež tetra-GOS. Predvidevajo, da je $\mathrm{pH}$ pomemben parameter pri razmerju transgalaktozilacijske in hidrolitične aktivnosti encima, s pomočjo spreminjanja tudi drugih parametrov pa je mogoče povečati sintezo zaželenih GOS (González-Delgado in sod., 2016). Geiger in sod. (2016) so uporabili $\beta$-galaktozidazo iz bakterij vrste Streptococcus thermophilus, izraženo v bakteriji Lactobacillus plantarum, za pretvorbo laktoze iz sirotke $\mathrm{v}$ GOS. Proces je potekal pri temperaturah $30^{\circ} \mathrm{C}$ in $50^{\circ} \mathrm{C}$. Hidroliza laktoze je potekala hitreje pri $50^{\circ} \mathrm{C}$ ter je bila končana po dveh urah, medtem ko je pri $37^{\circ} \mathrm{C}$ potekala pet ur. Pri začetni koncentraciji laktoze $50 \mathrm{~g} \mathrm{l}^{-1}$ je bil izkoristek pri $37^{\circ} \mathrm{C} 80 \%$. Z višjo začetno koncentracijo laktoze $205 \mathrm{~g} \mathrm{l}^{-1}$ je bil izkoristek po šestih urah pri $50^{\circ} \mathrm{C}$ in po devetih urah pri $37^{\circ} \mathrm{C}$ kar $95 \%$. Rezultati raziskave nakazujejo, da je iz dveh kg laktoze ali treh kg sirotkinega permeata $\mathrm{z}$ uporabo približno $100 \mathrm{kU}$ encima mogoče proizvesti $1 \mathrm{~kg}$ GOS (Geiger in sod., 2016).

Produkt trangalaktozilacijske aktivnosti $\beta$-galaktozidaze je tudi laktosaharoza, trisaharid s potencialom prebiotika. Sintetizirana je iz laktoze in saharoze s prenosom galaktozne enote $\mathrm{z}$ laktoze na molekulo saharoze (Díez-Municio in sod., 2014). Duarte in sod. (2017) so uporabili na hitozan imobilizirano $\beta$-galaktozidazo, pridobljeno iz bakterij vrste B. circulans, in preučili vpliv vrednosti $\mathrm{pH}$ in temperature na produkcijo laktosaharoze in ostalih oligosaharidov. Pri pH 7 in $\mathrm{T}=30^{\circ} \mathrm{C}$ je bila sestava produkta sledeča: $79 \mathrm{~g} \mathrm{l}^{-1}$ laktosaharoze, $37 \mathrm{~g} \mathrm{l}^{-1}$ galaktooligosaharidov in $250 \mathrm{~g} \mathrm{l}^{-1}$ skupnih oligosaharidov. Pri pH 5 in $\mathrm{T}=46^{\circ} \mathrm{C}$ pa so bile vrednosti 40,62 in $250 \mathrm{~g} \mathrm{l}^{-1}$. Rezultati so pokazali in potrdili, da lahko $\mathrm{s}$ spremembo reakcijskih pogojev spremenimo profil sestave končnega produkta

Transgalaktozilacijske reakcije imajo velik potencial 
za industrijske aplikacije na področju mlekarstva in živilstva nasploh. Zaradi pogosto slabega donosa GOS prihaja do večjega ostanka laktoze in monosaharidov, kot sta galaktoza in glukoza, ti pa zvišujejo energijsko vrednost ter znižujejo prebiotično vrednost živila (Crittenden in sod., 2002; Cheng in sod., 2006). Santibánez in sod. (2016) navajajo primer uporabe kvasovk vrste Kluyveromyes lactis za povečanje čistosti GOS, kar bi lahko prispevalo k večji uporabnosti in komercialni vrednosti GOS produktov. $\beta$-galaktozidazo iz nitaste glive vrste Aspergillus oryzae so uporabili za sintezo galaktooligosaharidov in laktuloze pri različnih temperaturah in $\mathrm{pH}$. Transgalaktozilacijska aktivnost se je povečala $\mathrm{z}$ višanjem temperature do $55^{\circ} \mathrm{C}$, $\mathrm{pH}$ med 2,5 in 5,5 pa ni imel večjega vpliva, medtem ko je transgalaktozilacijska aktivnost začela padati pri višjem $\mathrm{pH}$. Visoko učinkovito transgalaktozilacijsko aktivnost za sintezo $\beta(1 \rightarrow 3)$ oligosaharidov lahko pridobimo iz $\beta$-galaktozidaze iz govejih testisov, vendar pa je izolacija proteina iz živalskih tkiv dolgotrajna in draga (Schröder in sod., 2014).

\section{ZAKLJUČEK}

Encim $\beta$-galaktozidaza je zelo uporaben v živilski industriji, saj lahko pozitivno vpliva na prehransko vrednost živil, tehnološke procese predelave živil in je učinkovito orodje za zmanjševanje negativnega vpliva omenjene industrije na okolje. Rekombinantna produkcija in proteinski inženiring omogočata hitrejše pridobivanje encimov z željenimi lastnostmi ter visokim donosom. Možna je uporaba različnih tehnik imobilizacije, s katerimi lahko podaljšamo življenjsko dobo in stabilnost encima pri različnih vrednostih $\mathrm{pH}$ in temperaturah ter izboljšamo izkoristek procesa uporabe le-tega. Nekaterih lastnosti $\beta$-galaktozidaze, kot je transgalaktozilacijska aktivnost, še ne izkoriščamo na industrijski ravni zaradi nizkega izkoristka procesa, slabše čistosti končnega produkta ali neponovljivosti procesa, vendar število raziskav na tem področju narašča. Boljše poznavanje reakcijskih mehanizmov ter optimizacija procesov lahko $\mathrm{v}$ prihodnosti pripomoreta $\mathrm{k}$ raznovrstnejšim produktom boljše kakovosti. $\beta$-galaktozidaze bodo nedvomno ostale orodje $s$ širokim spektrom aplikacij, z rastočim trgom funkcionalne hrane pa bodo za živilsko industrijo postale še pomembnejše termostabilne $\beta$-galaktozidaze.

\section{$5 \quad$ VIRI}

Bailey, R. B., Benitez, T., Woodward, A. (1982). Saccharomyces cerevisiae mutants resistant to catabolite repression: use in cheese whey hydrolysate fermentation. Applied and Environmental Microbiology, 44, 631-639.

Beccera, M., Prado, S. D., Siso, M. I., Cerdan, M. E. (2001) New secretory strategies for Kluyveromyces lactis beta-galactosidase. Protein Engineering, Design and Selection, 14, 379-386. https://doi.org/10.1093/protein/14.5.379

Cauich-Rodriguez, J. V., Deb, S., Smith, R. J. (1996). Characterization of hydrogel blends of poly(vinyl pyrrolidone) and poly(vinyl alcohol-vinyl acetate). Journal of Materials Science: Materials and Medicine, 7(5), 269-272. https://doi. org/10.1007/BF00058565

Chen, W., Chen, H., Xia, Y., Yang, J., Zhao, J., Tian, F., Zhang, H. P., Zhang, H. (2009). Immobilization of recombinant thermostable beta-galactosidase from Bacillus stearothermophilus for lactose hydrolysis in milk. Journal of Dairy Science, 92, 491-498. https://doi.org/10.3168/jds.2008-1618

Chen, W., Chen, H., Xia, Y., Zhao, J., Tian, F., Zhang, H. (2008). Production, purification and characterization of a potential thermostable galactosidase for milk lactose hydrolysis from Bacillus stearothermophilus. Journal of Dairy Science, 91, 1751-1758. https://doi.org/10.3168/jds.2007-617

Cheng, C., Yu, M., Cheng, T., Sheu, D., Duan, K., Tai, W. (2006). Production of high-content galacto-oligosaccharide by enzyme catalysis and fermentation with Kluyveromyces marxianus. Biotechnology Letters, 28(11), 793-7971. https://doi. org/10.1007/s10529-006-9002-1

Cieśliński, H., Kur, J., Bialkowska, A., Baran, I., Makowski, K., Turkiewicz, M. (2005). Cloning, expression, and purification of a recombinant cold-adapted beta-galactosudase from antarctic bacterium Pseudoaltermonas sp. 22b. Protein Expression and Purification, 39, 27-34. https://doi. org/10.1016/j.pep.2004.09.002

Córdova, A., Astudillo, C., Santibañez, L., Cassano, A., RubyFigueroa, R., Illanes, A. (2017). Purification of galactooligosaccharides (GOS) by three-stage serial nanofiltration units under critical transmembrane pressure conditions. Chemical Engineering Research and Design, 117, 488-499. https://doi.org/10.1016/j.cherd.2016.11.006

Coté, A., Brown, W. A., van Walsum, G. P. (2004). Hydrolysis of lactose in whey permeate for subsequent fermentation to ethanol. Journal of Dairy Science, 87, 1608-1620. https://doi.org/10.3168/jds.S0022-0302(04)73315-9

Crittenden, R., Playne, M. (2002). Purification of food-grade oligosaccharides using immobilised cells of Zymomonas mobilis. Applied Microbiology and Biotechnology, 58(3), 297-302. https://doi.org/10.1007/s00253-001-0886-3

Daabrowski, S., Sobiewska, G., Maciuńska, J., Synowiecki, J., Kur, J. (2000). Cloning, expression, and pufirication of the His(6)-tagged thermostable beta-galactosudase from Pyrococcus woesei in Escherichia coli and some properties of the isolated enzyme. Protein Expression and Purification, 19, 107-112. https://doi.org/10.1006/prep.2000.1231

Dagbagli, S., Goksungur, Y. (2008). Optimization of $\beta$-galactosidase production using Kluyveromyces lactis NRRL Y-8279 by response surface methodology. Electronic Journal of Biotechnology, 11(4). https://doi.org/10.2225/ vol11-issue4-fulltext-12

Delzenne, N. M., Kok, N. N. (2003). Oligosaccharides: state of the art. British Journal of Nutrition, 62, 177-182. 
https://doi.org/10.1079/PNS2002225

Díez-Municio, M., Herrero, M., Olano, A., Moreno, F. J. (2014). Synthesis of novel bioactive lactose-derived oligosaccharides by microbial glycoside hydrolases. Microbial Biotechnology, 7(4), 315-331. https://doi.org/10.1111/17517915.12124

Domingues, L., Lima, N., Teixeira, J. A. (2005). Lactose hydrolysis by $\beta$-galactosidase production by yeast in a continuous high cell density reactor. Process Biochemistry, 40, 1151-1154. https://doi.org/10.1016/j.procbio.2004.04.016

Domingues, L., Teixeira, J. A., Penttilä, M., Lima, N. (2002). Construction of a flocculent Saccharomyces cerevisiae strain secreting high levels of Aspergilus niger beta-galactosidase. Applied Microbiology and Biotechnology, 58, 645650. https://doi.org/10.1007/s00253-002-0948-1

Duan, X., Shubing, H., Xuhui, Q., Zhengbiao, G., Jing, W. (2017). Optimal extracellular production of recombinant Bacillus circulans $\beta$-galactosidase in Escherichia coli BL21(DE3). Process Biochemistry, 53, 17-24. https://doi.org/10.1016/j.procbio.2016.11.008

Duarte, L. S., Schöffer, J. N., Lorenzoni, A. S. G., Rodrigues, R. C., Rodrigues, E., Hertz, P. H. (2017). A new bioprocess for the production of prebiotic lactosucrose by an immobilized $\beta$-galactosidase. Process Biochemistry, 1-15. https://doi.org/10.1016/j.procbio.2017.01.015

Dwevedi, A., Kayastha, A. M. (2009). Optimal immobilization of $\beta$-galactosidase from Pea (PsBGal) onto Sephadex and chitosan beads using response surface methodology and its applications. Bioresource Technology, 100, 2667-2675. https://doi.org/10.1016/j.biortech.2008.12.048

Elnashar, M., Yassin M. A., Moneim, A. E. A., Bary, E. M. A. (2010). Surprising Performance of Alginate Beads for the Release of Low-Molecular-Weight Drugs. Journal of Applied Polymer Science, 116(5), 3021-3026. https://doi.org/10.1002/app.31836

Fan, Y., Hua, X., Feng, Q. S., Dong, J., Zhao, W., Jin, Z, Yang, R. (2015). Cloning, expression and structural stability of a cold-adapted $\beta$-galactosidase from Rahnella sp. R3. Protein Expression and Purification, 115, 158-164. https://doi.org/10.1016/j.pep.2015.07.001

Gänzle, M. G., Loponen, J., Gobbetti, M. (2008). Proteolysis of sourdough fermentations: Mechanisms and potential for improved bread quality. Trends in Food Science and Technology, 19, 513-521. https://doi.org/10.1016/j.tifs.2008.04.002

Geiger, B., Nguyen, H. M., Weing, S., Nguyen, H. A., Lorenz, C., Kittl, R., ... Nhuyen, T. H. (2016). From by-product to valuable components: Efficient enzymatic conversion of lactose in whey using $\beta$-galactosidase from Streptococcus thermophilus. Biochemical Engineering Journal, 116, 45-53. https://doi.org/10.1016/j.bej.2016.04.003

Genari, A. N., Passos F. V., Passos F. M. (2003). Configuration of a bioreactor for milk lactose hydrolysis. Journal of Dairy Science, 86, 2783-2789. https://doi.org/10.3168/jds.S00220302(03)73875-2

González-Delgado, I., López, Muñoz, M. J., Morales, G., Segura, Y. (2016). Optimisation of the synthesis of high galactooligosaccharides (GOS) from lactose with $\beta$-galactosidase from Kluyveromyces lactis. Intertnational Dairy Journal, 61, 211-219. https://doi.org/10.1016/j.idairyj.2016.06.007
Gosling, A, Stevens, G. W., Barber A. R., Kentish S. E., Gras, S. L. (2010). Recent advances refining galactooligosaccharide production from lactose. Food chemistry, 121(2), 307-318. https://doi.org/10.1016/j.foodchem.2009.12.063

Grossova, Z., Rosenberg., M., Rebroš, M. (2008). Perspectives and application of immobilised beta-galactosidase in food industry - a review. Chech Journal of Food Sciences, 26(1), $1-14$.

Guerrero, C., Vera, C., Conejeros, R., Illanes, A. (2015). Transgalactosylation and hydrolytic activies of commercial preparations of $\beta$-galactosidase for the synthesis of prebiotic carbohydrates. Enzyme and Microbial Technology, 70, 9-17. https://doi.org/10.1016/j.enzmictec.2014.12.006

Guerrero, C., Vera, C., Illanes, A. (2017). Synthesis of lactulose in batch and repeated-batch operation with immobilized $\beta$-galactosidase in different agarose functionalized supports. Bioresurce Technology, 230, 56-66. https://doi.org/10.1016/j.biortech.2017.01.037

Guerrero, C., Vera, C., Plou, F., Illanes, A. (2011). Influence of reaction conditions on the selectiviry of the synthesis of lactulose with microbial $\beta$-galactosidases. Journal of $\mathrm{Mo}$ lecular Catalysis B: Enzymatic, 72(3-4), 206-212. https://doi.org/10.1016/j.molcatb.2011.06.007

Guimarães, P. M. R., Teixeira, J. A., Domingues, L. (2010). Fermentation of lactose to bio-ethanol by yeasts as part of integrated solutions for the valorization of cheese whey. Biotechnology Advances, 28, 375-384. https://doi.org/10.1016/j. biotechadv.2010.02.002

Hamilton-Miller, J. M. (2004). Probiotics and prebiotics in the elderly. Postgraduate Medical Journal, 80(946), 447-451. https://doi.org/10.1136/pgmj.2003.015339

Heyman, M. B. (2006). Lactose intolerance in infants, children and adolescents. Pediatrics, 118 (3), 1279-1286. https://doi.org/10.1542/peds.2006-1721

Hsu, C. A., Yu, R. C., Chou, C. C. (2005). Production of betagalactosidase by Bifidobacteria as influenced by various culture conditions. International Journal of Food Microbiology, 104(2), 197-206. https://doi.org/10.1016/j.ijfoodmicro.2005.02.010

Huerta, L. M., Vera, C., Guerrero, C., Wilson, L., Illanes, A. (2011). Synthesis of galacto-oligosaccharides at very high lactose concentrations with immobilized $\beta$-galactosidase from Aspergillus oryzae. Process Biochemistry, 46, 245-252. https://doi.org/10.1016/j.procbio.2010.08.018

Husain, Q. (2010). Beta galactosidases and their potential applications: a review. Critical Reviews in Biotechnology, 30 (1), 41-62. https://doi.org/10.3109/07388550903330497

Institute for Quality and Efficiency in Health Care. (2015). Lactose intolerance: Overview. IQWiG. Pridobljeno iz https:// www.ncbi.nlm.nih.gov/pubmedhealth/PMH0072452/

Jin, Y., Parashar, A., Mason, B., Bressler., D. C. (2016). Simultaneous hydrolysis and co-fermentation of whey lactose with wheat for ethanol production. Bioresource Technology, 221, 616-624. https://doi.org/10.1016/j.biortech.2016.09.063

Jokar, A. in Karbassi, A. (2009). Determination of proper conditions fort the production of crude beta-galactosidase using Lactobacillus delbrueckii ssp. bulgaricus. Journal of Agricultural Science and Technology, 11, 301-308.

Jokar, A., Karbassi, A. (2011). In-house Production of lactose- 
hydrolysed milk by beta-galactosidase from Bacillus bulgaricus. Journal of Agrocultural Science and Technology, 13, 577-584.

Kishore, D., Kayastha, A. M. (2012). Optimisation of immobilisation conditions for chich pea $\beta$-galactosidase (CpGAL) to alkylamine glass using response surface methodology and its applicatons in lactose. Food chemistry, 143, 1650-1657. https://doi.org/10.1016/j.foodchem.2012.03.055

Klein, M. P., Hackenhaar, C. R., Lorenzoni, A. S. G., Rodrigues, R. C., Costa, T. M. H., Ninow, J. L., Hertz, P. F. (2016). Chitosan crosslinked with genipin as support matrix for application on food process: Support characterization and of $\beta$-D-galactosidase immobilization. Carbohydrate Polymers, 137, 184-190. https://doi.org/10.1016/j.carbpol.2015.10.069

Kosseva, M. R., Panesar, P. S., Kaur, G., Kennedy, J. F. (2009). Use of immobilised biocatalysts in the processing of cheese whey. International Journal of Biological Macromolecules, 45, 437-447. https://doi.org/10.1016/j.ijbiomac.2009.09.005

Krajewska, B. (2004). Application of chitin - and chitosanbased materials for enzyme immobilizations: A review. Enzyme and Microbial Technology, 35(2-3), 126-139. https://doi.org/10.1016/j.enzmictec.2003.12.013

Li, X. E., Lopetcharat, K., Qiu, Y., Drake, M. A. (2015). Sugar reduction of skim chocolate milk and viability of alternative sweetening trough lactose hydrolysis. Journal of Dairy Science, 98, 1455-1466. https://doi.org/10.3168/jds.2014-8490

Li, Y., Lu, L., Wang, H., Xu, X., Xiao, M. (2009). Cell surface engineering of a $\beta$-galactosidase for galactooligosaccharide synthesis. Applied and environmental microbiology, 75(18), 5938-5942. https://doi.org/10.1128/AEM.00326-09

Lyons, T. P., Cunningham, J. D. (1980). Fuel alcohol from whey. American Dairy Products Review, 42(11), 42A-42E.

Mahdian, S. M. A., Karimi, E., Tanipour, M. H., Parizadeh, S. M. R., Ghayour-Mobarhan, M., Bazaz, M. M., Mashkani, B. (2016). Expression of a functional cold active $\beta$-galactosidase from Planococcus sp-L4 in Pichia pastoris. Protein Expression and Purification, 125, 19-25. https://doi.org/10.1016/j.pep.2015.09.008

Muzzarelli, A. A. R. (2009). Carbohydrate polimers, 77(1), 1-9. Neri, D. F. M., Balcao, V. M., Carneiro-da-Cunha, M. G., Carvalho, Jr L. B., Teixeira, J. A.. (2008). Immobilization of $\beta$ galactosidase from Kluyveromyces lactis onto a polysiloxane-polyvinyl alcohol magnetic (mPOS-PVA) composite for lactose hydrolysis. Catalysis Communications, 4, 234239. https://doi.org/10.1016/j.catcom.2008.05.022

Neri, D. F. M., Balcão, V. M., Costa, R. S., Rocha, I. C. A. P., Ferreira, E. M. F. C., Torres, D. P. M., Rodrigues, R. D. M., ... Teixieira, J. A. (2009). Galacto-oligosaccharides production during lactose hydrolysis by free Aspergillus oryzae -galactosidase and immobilized on magnetic polysiloxane-polyvinyl alcohol. Food Chemistry, 115(1), 92-99.

https://doi.org/10.1016/j.foodchem.2008.11.068

Obed Otieno, D. (2010). Synthesis of $\beta$-galactooligosaccharides from lactose using microbial $\beta$-galactosidase. Comprehensive Reviews In Food Science and Food Safety, 9, 471-482. https://doi.org/10.1111/j.1541-4337.2010.00121.x

Oliveira, C., Giumarães M.R. P., Domingues, L. (2011). Recombinant microbial systems for improved $\beta$-galactosidase production and biotechnological applications. Biotechnology Advances, 29, 600-609. https://doi.org/10.1016/j.biotechadv.2011.03.008

Pan, Q., Zhu, J., Liu, L., Chong, Y., Hu, F., Li, J. (2010). Functional identificaton of a putative beta-galactosidase gene in the special lac gene cluster of Lactobacillus acidophilus. Current Microbiology, 60, 172-178. https://doi.org/10.1007/ s00284-009-9521-9

Panesar P. S., Panesar, R., Singh, R. S., Kennedy, J. F. in Kumar, H. (2006). Microbial production, immobilization and applications of $\beta$-galactosidase in food processing industries. Journal of Chemical Technology and Biotechnology, 81, 530-543. https://doi.org/10.1002/jctb.1453

Panesar, P. S., Kumari, S., Panesar, R. (2010). Potential applications of immobilized $\beta$-galactosidase in food processing industries. Enzyme Research, 16 str. https://doi. org/10.4061/2010/473137

Panesar, R., Panesar, P. S., Singh, R. S., Bera, M. B. (2007). Applicability of alginate entrapped yeast cells for the production of lactose-hydrolyzed milk. Journal of Food Process Engineering, 30(4), 472-484. https://doi.org/10.1111/ j.1745-4530.2007.00127.x

Patel, S., Goyal, A. (2010). The current trends and future perspectives of prebiotics research: a review. 3 Biotech, 2(2), 115-125. https://doi.org/10.1007/s13205-012-0044-X

Richmond, M. L., Gray, J. I., Stine, C. M. (1981). $\beta$ galactosidase: review of recent research related to technological application, nutritional concerns, and immobilization. Journal of Dairy Science, 64, 1759-1771. https://doi.org/10.3168/jds. S0022-0302(81)82764-6

Rueda, N., Dos Santos, C. S., Rodrigues, M. D., Albuquerque, T. L., Barbosa, O., Torres, R., Ortiz, C., Fernandez-Lafuente, R. (2016). Reversible immobilisation of lipases on ocrylglutamic agarose beads: a mixed absorbtion that reinforces enzyme immobilization. Journal of Molecular Catalysis B: Enzymatic, 128, 10-18. https://doi.org/10.1016/j.molcatb.2016.03.002

Sabater, C., Prodanov, M., Olano, A., Corzo, N., Monrilla, A. 2015. Quantification of prebiotics in commercial infant formulas. Food Chemistry, 194, 6-11. https://doi.org/10.1016/j. foodchem.2015.07.127

Santibáñez, L., Fernández-Arrojo, L., Guerrero, C., Plou, F. J., Illanes, A. (2016). Removal of lactose in crude galacto-oligosaccharides by $\beta$-galactosidase from Kluyveromyces lactis. Journal of Molecular Catalysis B: Enzymatic, 133, 85-91. https://doi.org/10.1016/j.molcatb.2016.07.014

Schröder, S., Kröger, L., Mattes, R., Thiem, J. (2014). Transglycosylations employing recombinant $\alpha$ and $\beta$-galactosidases and novel donor substrates. Carbohydrate Research, 403, 157-166. https://doi.org/10.1016/j.carres.2014.05.005

Sheik, S. Asraf, Gunasekaran P. (2010). Current trends of $\beta$-galactosidase research and application. Current Research, Technology and Education Topics in Applied Microbiology and Microbial Biotechnology. In A. Mendez-Villas (Ed), Formatex Microbiology Series 2(1). (pp. 880-890).

Shen, Q., Zhang, Y., Yang, R., Pan, S., Dong, J., Fan, Y., Han, L. (2016) Enhancement of isomerization activity and lactulose production of cellobiose 2-epimerase from Caldicel- 
lulosiruptor saccharolyticus. Food Chemistry, 207, 60-67. https://doi.org/10.1016/j.foodchem.2016.02.067

Siso, M. I. G. (1996). The biotechnological utilization of cheese whey: a review. Bioresourse Technology, 57, 1-11. https:// doi.org/10.1016/0960-8524(96)00036-3

Siso, M.I.G., Ramil, E., Cerdan, M.E. and Picos, M.A.F. (1996). Respirofermentative metabolism in Kluyveromyces lactis: ethanol production and the Crabtree effect. Enzyme Microbial Technology, 18, 585-595. https://doi.org/10.1016/01410229(95)00151-4

Song C., Chi, Z., Li, J., Wang, X. (2010). Beta-galactosidase production by the psychotolerant yeast Guehomyces pullulans 17-1 isolated from sea sediment in Antarctica and lactose hydrolysis. Bioprocess and Biosystems Engineering, 33, 1025-1031. https://doi.org/10.1007/s00449-010-0427-5

Srivastava, A., Mishra, S., Chand, S. (2015). Transgalactosylation of lactose for synthesis of galacto-oligosaccharides using Kluyveromyces marxianus NCIM 3551. New Biotechnology, 32(4), 412-418. https://doi.org/10.1016/j. nbt.2015.04.004

Strnad, S., Šauperl, O., Fras, L., Jazbec, A. (2007). Hitozan vsestransko uporaben biopolimer. Tekstilec, 50(10-12), 243-261.

Terrell. S. L., Bernard, A., Bailey R. B. (1984). Ethanol from whey - continuous fermentation with a catabolite repression-resistant Saccharomyces cerevisiae mutant. Applied and Environmental Microbiology, 48, 577-80.

Urrutia, P., Rodrigues-Colinas, B., Fernandez-Arrojo, L., Ballesteros, A., Wilson, L., Illanes, A., Plou, F. J. (2013). Detailed analysis of galactooligosaccharides synthesis with $\beta$-galactosidase from Aspergillus oryzae. Journal of Agricultural and Food Chemistry, 61(5), 1081-1087. https://doi.org/10.1021/jf304354u

Vera, C., Guerrero, C., Illanes, A. (2011). Determination of the transgalactosylation activity of Aspergillus oryzae $\beta$-galactosidase: effect of $\mathrm{pH}$, temperature, and galactose and glucose concentrations. Carbohydrate Research, 346(6), 745-752. https://doi.org/10.1016/j.carres.2011.01.030

Wahba, M. I. (2016). Treated calcium pectinate beads for the covalent immobilization of $\beta$-D-galactosidase. International Journal of Biological Macromolecules, 91, 877-886. https://doi.org/10.1016/j.ijbiomac.2016.06.044

Watson, A. L., Chiu, N. H. L. (2016). Flourometric cell-based assay for $\beta$-galactosidase activity in probiotic gram-positive bacterial cells - Lactobacillus helveticus. Journal of Microbiological Methods, 128, 58-60. https://doi.org/10.1016/j. mimet.2016.06.030

Yamanda, M., Chiba, S., Endo, Y., Isobe, K. (2017). New alkalophilic $\beta$-galactosidase with high activity in alkaline $\mathrm{pH}$ region from Teratosphaeria acidotherma AIU BGA-1. Journal of Bioscience and Bioengineering, 123(1), 15-19. https://doi.org/10.1016/j.jbiosc.2016.07.003

Yang, M., Silva, M. (1995). Novel products and new technologies for use of a familiar carbohydrate, milk lactose. Journal of Dairy Science, 78, 2541-2562. https://doi.org/10.3168/ jds.S0022-0302(95)76884-9

Yuan, T. Z., Yang, P. L., Wang, Y. R., Meng, K., Luo, H. Y., Zhang, W. (2008). Heterologous expression of a gene encoding a thermostable beta-galactosidase from Alicyclobacillus acidocaldarius. Biotechnology Letters, 30, 343-348. https://doi.org/10.1007/s10529-007-9551-y

Zadow, J. G. (1984). Lactose: properties and uses. Journal of Dairy Science, 67, 2654-2679. https://doi.org/10.3168/jds. S0022-0302(84)81625-2

Zucca, P., Sanjust, E. (2014). Inorganic materials as supports for covalent enzyme immobilization: methods and mechanisms. Molecules, 19, 14139-14194. https://doi.org/10.3390/molecules190914139 